\title{
Decelerating burst and complex repetitive discharges in the striated muscle of the urethral sphincter, associated with urinary retention in women
}

\author{
CLARE J FOWLER, RS KIRBY, MJG HARRISON \\ From the Reta Lila Weston Institute of Neurological Studies, Middlesex Hospital Medical School, and the \\ Department of Urology, Middlesex Hospital, London UK
}

SUMMARY A type of electromyographic activity, formerly referred to as "pseudomyotonia", can be recorded from the striated muscle of the urethral sphincter using a concentric needle electrode. There are two components to this activity, complex repetitive discharges and decelerating bursts. The latter usually dominate recordings and sound very like myotonic discharges. Analysis of these discharges indicates that they are a form of "bizarre repetitive discharge", and as such, result from ephaptic spread of excitation between muscle fibres rather than from excitation arising in the terminal branches of the motor axon. Profuse activity of this type has been found in 15 women with symptoms of urethral dysfunction, including 11 with urinary retention. It is suggested that this activity is associated with a failure of urethral sphincter relaxation.

The striking EMG activity that may be recorded from the urethral sphincter with a needle electrode, was first reported as "pseudomyotonia" by DiBenedetto and Yalla in 1979.' Other reports of this activity in the urological literature have subsequently adopted the same terminology, ${ }^{2-4}$ with the exception of Dyro et al, ${ }^{5}$ who used the term "complex repetitive discharges". Because such confusion surrounds the term "pseudomyotonia", we have avoided it and in a recent publication referred to the activity as "complex repetitive discharges" plus "decelerating burst" discharges. ${ }^{6}$ Although the term "complex repetitive discharges" introduced by Dyro et $\mathrm{al}^{5}$ is very appropriate, it does not encompass the dominant component of such recordings, the bursts of activity which have a decelerating rate and therefore sound so like myotonic discharges. We discuss later the electromyographic terminology used to describe various abnormal discharges recorded from muscle.

The significance of decelerating burst and complex repetitive discharge activity in the urethral sphincter has been obscure. It has been reported in adults and children with a wide range of urological Address for reprint requests: Dr CJ Fowler, The Middlesex Hospital Medical School, London W1N 8AA, UK

Received 27 November 1984 and in revised form 14 February 1985.

Accepted 16 February 1985. complaints. $^{235}$ We have previously reported th 8 findings of profuse amounts of this EMG activity i five women who presented with the isolated symptom of persisting urinary retention. ${ }^{6}$ We suggested that this type of EMG activity may be associated. with a failure of relaxation of the sphincter, with important functional consequences.

We report here a larger group of patients in whom we have recorded decelerating bursts plus complex repetitive discharges. For each patient we have tried to quantitate the amount of abnormal EMG activity and consider this in the context of the individual's urological symptoms.

\section{Method}

Details of the method we have used to record EMG activity with a concentric needle electrode from the urethral sphincter have already been published. ${ }^{7}$ Motor units in the striated muscle of the urethral sphincter fire tonically and electrical silence in this muscle occurs just prior to, and during micturition. Motor units from this tonically firing population were isolated using a trigger and delay line, and measurements made of amplitude, duration and polyphasicity from film.

Decelerating bursts plus complex repetitive discharges were found to be infrequent in some patients but profuse in others. To quantify this activity in each patient we have used the following simple scale:

I: transient bursts occurring only on needle movement.

II: bursts occurring with needle movement but also 
induced by coughing, head raising or leg movement (that is, manoeuvres which usually increase the firing rate of the tonic background activity.)

III: as with II but also heard, albeit infrequently, occurring spontaneously.

IV: heard occurring spontaneously and profusely during the recording.

$\mathrm{V}$ : as in IV but also heard distantly as soon as the needle was introduced into the periurethral tissue, and before "sharp" motor units can be recorded.

For detailed analysis of the electrical characteristics of the decelerating bursts and complex repetitive discharges, recordings were made on a tape recorder (Racal Store 4DS) and played back through an MS6 (Medelec) with a trigger and delay line.

\section{Patients}

Approximately 150 urethral sphincter EMG studies using a CNE have now been carried out. The use of this technique has been mainly confined to the investigation of patients with symptoms suggestive of lower motor neuron lesions of the urethra and bladder. Most patients had a single concentric needle electrode EMG of the urethral sphincter, but some had multiple studies, particularly those in whom we recorded decelerating bursts and complex repetitive discharges. The number of studies for an individual is given in table 1 .

The patients included twelve with cauda equina lesions, 11 with Shy Drager syndrome, six with Parkinson's disease, 12 with pelvic nerve injury, and one with each of the following conditions; neurosyphilis, diabetes, syringomyelia, spina bifida, and sacral agenesis. In addition we have studied 57 patients referred for sphincter EMG as part of investigations of disorders of micturition such as retention, incontinence and frequency. Fourteen control subjects also gave informed consent to be studied.

\section{Results}

\section{Findings in patients}

Table 1 summarises data from all patients in whom decelerating bursts plus complex repetitive discharges have been recorded. Brief bursts of complex repetitive discharge or decelerating burst (Grade I or II) occurred on needle movement in one of 14 control subjects and one woman with urinary frequency. It was also found in four patients who were known to have neurological disease with involve-

Table 1 Patients in whom decelerating bursts and complex repetitive discharges (CRDs) were recorded. (UTIS = urinary tract infections)

\begin{tabular}{|c|c|c|c|c|c|c|c|}
\hline - Case & $\operatorname{Sex}$ & Age (yr) & $\begin{array}{l}\text { Associated neurological } \\
\text { disease }\end{array}$ & Symptoms & $\begin{array}{l}\text { Number of } \\
\text { EMG studies }\end{array}$ & $\begin{array}{l}\text { decelerating burst } \\
\text { + complex } \\
\text { repetitive discharges } \\
\text { Grade I-V }\end{array}$ & $\begin{array}{l}\text { Evidence of } \\
\text { reinnervation }\end{array}$ \\
\hline $\begin{array}{r}1 \\
2 \\
3 \\
4 \\
5 \\
+6 \\
7\end{array}$ & $\begin{array}{l}\mathbf{F} \\
\mathbf{F} \\
\mathbf{F} \\
\mathbf{M} \\
\mathbf{M} \\
\mathbf{M}\end{array}$ & $\left.\begin{array}{l}61 \\
48 \\
35 \\
35 \\
43 \\
68 \\
56\end{array}\right\}$ & $\begin{array}{l}\text { Control } \\
\text { None } \\
\text { Not known } \\
\text { Not known } \\
\text { Cauda equina injury } \\
\text { Shy Drager syndrome }\end{array}$ & $\begin{array}{l}\text { None } \\
\text { Frequency } \\
\text { Retention } \\
\text { Retention } \\
\text { Retention } \\
\text { Incontinence } \\
\text { Incontinence }\end{array}$ & $\begin{array}{l}1 \\
1 \\
2 \\
1 \\
1 \\
2 \\
1\end{array}$ & $\begin{array}{l}+ \\
+ \\
+ \\
+ \\
+ \\
+ \\
+\end{array}$ & $\begin{array}{l}\text { No } \\
\text { No } \\
\text { Yes } \\
\text { Yes } \\
\text { Yes } \\
\text { Yes } \\
\text { Yes }\end{array}$ \\
\hline $\begin{array}{r}8 \\
9 \\
10 \\
11 \\
12 \\
13 \\
14 \\
15\end{array}$ & $\begin{array}{l}\mathbf{F} \\
\mathbf{F} \\
\mathbf{F} \\
\mathbf{F} \\
\mathbf{M} \\
\mathbf{F} \\
\mathbf{F} \\
\mathbf{F}\end{array}$ & $\begin{array}{l}22 \\
52 \\
48 \\
74 \\
32 \\
39 \\
59 \\
58\end{array}$ & $\begin{array}{l}\text { None } \\
\text { None } \\
\text { None } \\
\text { Pelvic nerve injury } \\
\text { Spina bifida } \\
\text { None } \\
\text { None } \\
\text { None }\end{array}$ & $\begin{array}{l}\text { Incontinence } \\
\text { Frequency \& urgency } \\
\text { Voiding difficulties } \\
\text { Voiding difficulties } \\
\text { Retention } \\
\text { Retention } \\
\text { Retention } \\
\text { Retention }\end{array}$ & $\begin{array}{l}1 \\
1 \\
2 \\
1 \\
1 \\
3 \\
3 \\
2\end{array}$ & $\begin{array}{l}++ \\
++ \\
++ \\
++ \\
+++ \\
+++ \\
+++ \\
+++\end{array}$ & $\begin{array}{l}\text { No } \\
\text { Yes } \\
\text { No } \\
\text { Yes } \\
\text { Yes } \\
\text { No } \\
\text { CRDS } \\
\text { CRDS }\end{array}$ \\
\hline $\begin{array}{l}16 \\
17 \\
18 \\
19\end{array}$ & $\begin{array}{l}\mathbf{F} \\
\mathbf{F} \\
\mathbf{F}\end{array}$ & $\begin{array}{l}78 \\
41 \\
28 \\
29\end{array}$ & $\begin{array}{l}\text { None } \\
\text { None } \\
\text { None } \\
\text { None }\end{array}$ & $\begin{array}{l}\text { Recurrent UTIS } \\
\text { Retention } \\
\text { Retention } \\
\text { Retention }\end{array}$ & $\begin{array}{l}1 \\
2 \\
2 \\
4\end{array}$ & $\begin{array}{l}++++ \\
++++ \\
++++ \\
++++\end{array}$ & $\begin{array}{l}\text { CRDS } \\
\text { No } \\
\text { No } \\
\text { No }\end{array}$ \\
\hline $\begin{array}{r}20 \\
21 \\
22 \\
23 \\
\times 24 \\
25 \\
26 \\
27\end{array}$ & $\begin{array}{l}\mathbf{F} \\
\mathbf{F} \\
\mathbf{F} \\
\mathbf{F} \\
\mathbf{F} \\
\mathbf{F} \\
\mathbf{F} \\
\mathbf{F}\end{array}$ & $\begin{array}{l}21 \\
36 \\
31 \\
42 \\
37 \\
20 \\
24 \\
40\end{array}$ & $\begin{array}{l}\text { None } \\
\text { None } \\
\text { None } \\
\text { None } \\
\text { None } \\
\text { None } \\
\text { None } \\
\text { None }\end{array}$ & $\begin{array}{l}\text { Incomplete voiding } \\
\text { Low flow \& frequency } \\
\text { Voiding difficulties } \\
\text { Retention } \\
\text { Retention } \\
\text { Retention } \\
\text { Retention } \\
\text { Retention }\end{array}$ & $\begin{array}{l}2 \\
2 \\
4 \\
6 \\
1 \\
1 \\
1 \\
1\end{array}$ & $\begin{array}{l}+++++ \\
+++++ \\
+++++ \\
+++++ \\
+++++ \\
+++++ \\
+++++ \\
+++++\end{array}$ & $\begin{array}{l}\text { CRDS } \\
\text { CRDS } \\
\text { No } \\
\text { CRDS } \\
\text { No } \\
\text { CRDS } \\
\text { CRDS } \\
\text { CRDS }\end{array}$ \\
\hline
\end{tabular}


ment of sphincter innervation and another three patients who were thought to have evidence of reinnervation in the sphincter, as judged by the presence of abnormal motor units (although the cause of the innervation disorder was not known). In these circumstances the phenomenon should probably be regarded as a form of insertional activity, analogous to the fibrillations which may be induced by needle movement in skeletal muscle and to which little significance is attached.

With the single exception of a man with spina bifida, Grade III-V activity (that is, spontaneous decelerating bursts and complex repetitive discharges) was only found in women with symptoms attributable to urethral dysfunction, urinary retention being the commonest presenting complaint. All four women without urinary retention but with Grade IV-V decelerating burst and complex repetitive discharge activity, had disorders which could be attributed to impaired urethral relaxation and incomplete bladder emptying.

From the total number of 117 subjects in whom we carried out sphincter EMG, there were 19 women who had urinary retention, unassociated with a known neurological lesion (such as cauda equina injury). In 11 of these Grade III-V decelerating bursts and complex repetitive discharges were recorded (table 1). In the remaining eight women, two were found to have evidence of reinnervation
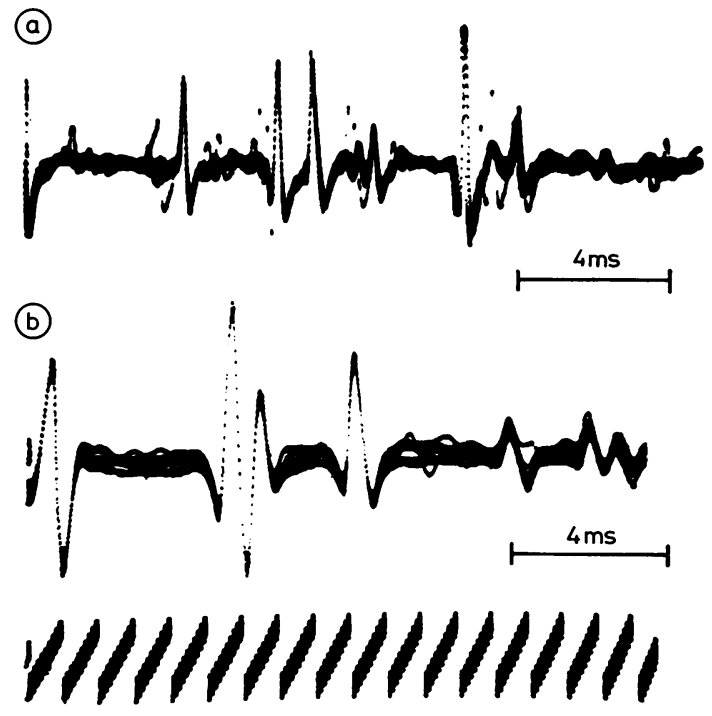

Fig 1 Repetitive discharges from urethral striated muscle. (a) Decelerating burst (DB) discharge, recorded with a concentric needle electrode. (b) Part of a complex from a decelerating burst discharge recorded with a single fibre electrode. Five traces superimposed using trigger circuit and delay lines. (see table 1). No abnormality of sphincter EMG could be found in six with retention.

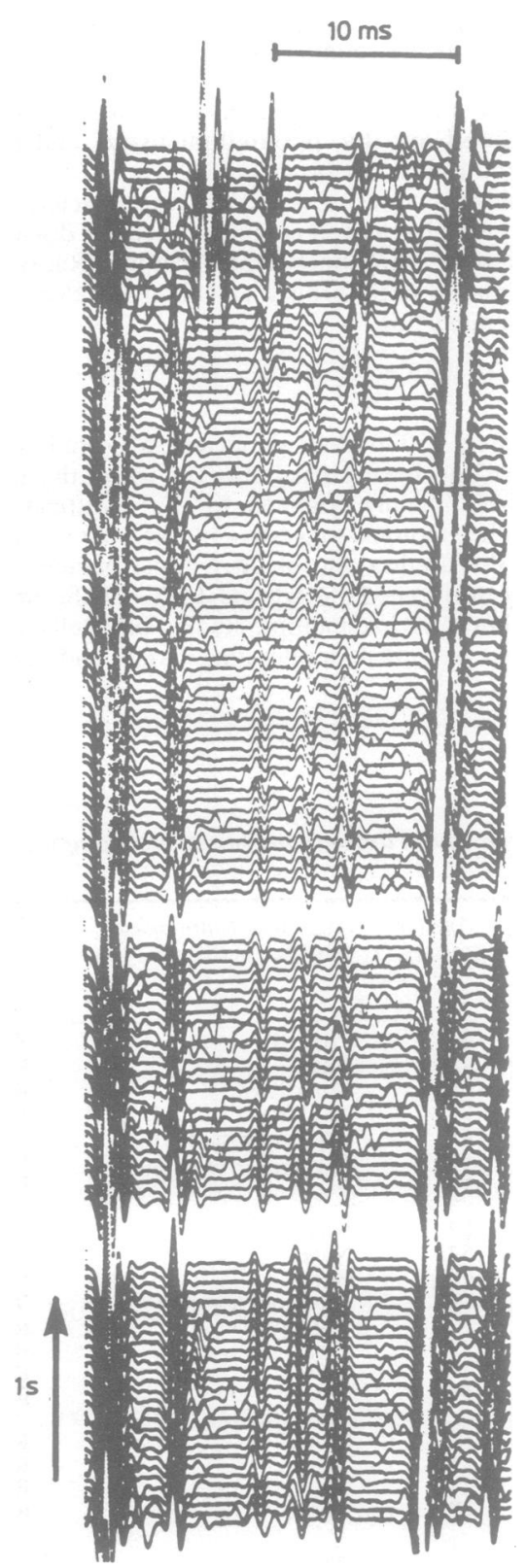

Fig 2 Successive sweeps of a decelerating burst discharge replayed from tape recording, showing a progressive increase in the intervals between the early components (used for triggering) and later components. The two gaps are caused by failure of triggering. The vertical time scale shows the direction and speed of paper movement. 
Electrical characteristics of decelerating bursts and complex repetitive discharges

When the needle is in close proximity to muscle fibres contributing to the activity, complex repetitive discharges produce a "buzzing" sound, whereas decelerating bursts sound like dive bombers or motor cycles. Distant decelerating bursts have been said to resemble the "the underwater chorus of whales." 2 Electrical activity produced by decelerating bursts appears to be well transmitted through tissue as their distant activity may be heard in some cases before the needle tip is recording sharp motor units. Remote discharging activity is better heard than seen.

In all patients with spontaneously occurring activity (that is, Grades III-V), we have heard both complex repetitive discharges and decelerating bursts. In one patient complex repetitive discharges were more common than decelerating bursts, but otherwise decelerating bursts dominated the recordings. Decelerating bursts may arise out of a background of normal tonically firing motor units, or may follow complex repetitive discharges. Complex repetitive discharges alone may also be heard but tend to occur in pseudo-rhythmic bursts with a frequency of $1-3 \mathrm{~Hz}$.

In a single patient (Case 23) we had the opportunity to record from the urethral sphincter as she was being anaesthetised for a urinary diversion procedure. Following induction with thiopentone, at a time when skeletal striated limb muscles were electrically silent but spontaneous respiration was still maintained, tonically firing motor units were recorded from the urethral sphincter; in addition decelerating bursts could also be recorded. With curarisation both decelerating bursts and tonic motor unit activity were lost.

Decelerating bursts and complex repetitive discharges recorded on tape and analysed on play back with the aid of a trigger and delay line show a high degree of stability exhibited by repetitively firing complexes (fig 1A and B). The low jitter of interpotential intervals of the early phases of a repetitively firing complex contribute to the remarkable repro- ducibility of the complexes, as shown by the superimposition of five complexes in fig $1 \mathrm{~A}$ and $\mathrm{B}$. Figure 2 shows an almost complete decelerating burst discharge and illustrates the uniform decrease in the rate of firing of the complex. It is this that generates the characteristic sound of decelerating bursts. In complex repetitive discharges deceleration is either less prominent or absent.

The duration of a repetitively firing complex may be $20 \mathrm{~ms}$, with as many as 10 component potentials. The amplitude of the activity is of the same order as the surrounding normal tonically firing motor units, that is between $100-400 \mu \mathrm{V}$. In a decelerating burst the complexes fire repetitively at a rate of $40-80 \mathrm{H}_{2}$ and a discharge may last for as long as 20 seconds, although 10 seconds is more usual. Complex repetitive discharges last approximately 1 second only.

\section{Discussion}

\section{Terminology}

Although the term "pseudomyotonia" has become well established in the urological literature ${ }^{4}$ there remains some confusion as to the type of underlying abnormality it implies. In electrophysiological texts some authorities use the term as a synonym for neuromyotonia $^{84}$ while others place it under the same heading as "bizarre high frequency discharges" 10 Table 2 summarises the essential electrophysiological characteristics of myotonia, bizarre high frequency discharges and neuromyotonia. Until there is agreement on the exact meaning of the term "pseudomyotonia", its use will continue to confuse. We therefore prefer the terms decelerating burst and complex repetitive discharge. Dyro et al ${ }^{\mathbf{s}}$ have already applied the term "complex repetitive discharge" to this activity. The additional term "decelerating burst", gives an indication of the striking and dominant activity that may be confused with myotonia.

The origin and spread of decelerating bursts and complex repetitive discharges

Our studies confirm the observations of

Table 2 Summary of electrophysiological characteristics of discharges in muscle.

\begin{tabular}{|c|c|c|c|c|}
\hline & Synonym & Discharge characteristics & Underlying abnormality & $\begin{array}{l}\text { Single fibre EMG } \\
\text { characteristics }\end{array}$ \\
\hline Myotonia & & $\begin{array}{l}\text { High-frequency, continuously } \\
\text { decreasing firing rate of single } \\
\text { muscle fibres }\end{array}$ & Instability of muscle membrane & Single discharges \\
\hline $\begin{array}{l}\text { Bizarre high } \\
\text { frequency discharge }\end{array}$ & $\begin{array}{l}\text { complex repetitive } \\
\text { discharge }\end{array}$ & $\begin{array}{l}\text { Multiple potentials rapidly firing } \\
\text { with increasing or decreasing } \\
\text { rate trends }\end{array}$ & $\begin{array}{l}\text { Ephaptic spread of excitation } \\
\text { between muscle fibres }\end{array}$ & $\begin{array}{l}\text { Jitter between spike } \\
\text { components too low } \\
\text { for neuromuscular } \\
\text { transmission }\end{array}$ \\
\hline Neuromyotonia & Isaac's syndrome & $\begin{array}{l}\text { Repetitive bursts with complex } \\
\text { waveforms }\end{array}$ & $\begin{array}{l}\text { Spontaneous firing in distal parts } \\
\text { of axonal tree }\end{array}$ & $\begin{array}{l}\text { Typical of neuromuscular } \\
\text { transmission }\end{array}$ \\
\hline
\end{tabular}


others, ${ }^{12-511}$ that this type of activity is not infrequently recorded from the urethral sphincter with a needle electrode. We previously suggested ${ }^{6}$ that this EMG abnormality was a form of neuromyotonia, thinking that the activity arose in distal branches of the motor axon. (see table 2) However, the IP jitter of complexes in neuromyotonia is typical of neuromuscular transmission and greater than that demonstrated here. ${ }^{12}$ We are now therefore of the view that this activity is a form of "bizarre highfrequency discharges",,$^{12}$ or "bizarre repetitive discharges".$^{13}$ The activity that we have recorded from the sphincter seems to differ from complex repetitive discharges recorded from striated skeletal mus$\mathrm{cle}^{13}$ in that profuse decelerating bursts usually dominate the recording from the urethral sphincter.

Stalberg and Trontelj argue that repetitive activity which shows less than $5 \mu$ s interpotential (IP) jitter can not arise via the motor end plates but must be due to ephaptic spread of excitation between low threshold sites from one muscle fibre to another. They also state that a uniformly decreasing firing rate is a feature of discharges initiated in muscle fibres. ${ }^{12}$ We have demonstrated that repetitive discharges in the urethral sphincter have a very low IP jitter in early components and that a decelerating rate of firing is a prominent feature of decelerating bursts. It thus seems probable that decelerating bursts and complex repetitive discharges result from ephaptic spread of excitation between muscle fibres. Dyro et al were also of this opinion. ${ }^{5}$ That decelerating bursts plus complex repetitive discharges could not be recorded in a curarised subject indicates that the bursts must at least be initiated by neuromuscular transmission.

The question as to what normally prevents spread of electrical excitation from activated motor units to other muscle fibres in healthy skeletal striated muscle, has been addressed by Willison. ${ }^{14}$ Muscle fibres within a motor unit are arranged in such a way that adjacencies are minimal. Thus the action currents of the hundreds of fibres which comprise a motor unit are distributed widely throughout the muscle. In addition the asynchronous nature of discharging motor neurons reduces the chances of many adjacent muscle fibres depolarising simultaneously. Only with collateral reinnervation can current densities reach sufficient magnitude to cause depolarisation of adjacent fibres. The high incidence of this type of ephaptic transmission in the urethral sphincter indicates that the muscle has a peculiar propensity to develop low threshold sites permitting spread of action currents between fibres.

In our studies special attention has been paid to detecting changes of reinnervation, as described in an earlier publication. ${ }^{7}$ It may be difficult to distin- guish between complex repetitive discharge and polyphasic motor units from traces obtained during imperfect recording conditions. However if complex waveforms were obtained at a time when decelerating bursts or complex repetitive discharges were heard, it was assumed that the waveform was not that of a polyphasic motor unit. Most significantly, profuse decelerating bursts plus complex repetitive discharges were not found in sphincter muscles in which there was clear evidence of collateral reinnervation. Of the patients in whom abnormal motor unit parameters indicated reinnervation ie those with the Shy Drager syndrome, or pelvic nerve or cauda equina lesions, ${ }^{7}$ only a small proportion (four out of 34) had Grade I or II decelerating bursts plus complex repetitive discharges. We conclude from this, that decelerating bursts plus complex repetitive discharges do not simply accompany reinnervation. This is a further distinction between sphincter decelerating burst plus complex repetitive discharges and skeletal muscle complex repetitive discharges, since the latter are recorded from denervated or dystrophic muscle. ${ }^{13}$

\section{Urinary retention in women}

Successful voiding is the result of the co-ordinateक relaxation of the sphincter and contraction of the bladder. In the absence of a gross neurological oro anatomical abnormality, the cause of urinary reten tion in women is unknown. Obstructed urinaryo outflow in women is usually thought to arise at the bladder neck or distal urethra. The distal urethra is the more common urodynamically proven site for? obstruction $^{15}$ and this corresponds with the anatomical site of the striated muscle of the urethral sphincter.

Various authors have expressed the view that isolated urinary retention in some women is a psychogenic disorder, ${ }^{16-18}$ whilst others ${ }^{19}$ have attributed such retention to silent lumbar disc protrusion. An alternative theory was proposed by $\mathrm{Raz}$ and Smith. ${ }^{20}$ They described three women with urinary retention whose urodynamic studies demonstrated "external sphincter spasticity". They suggested that sphincter spasticity was much more common in female patients than previously considered. No neurophysiological explanation for isolated spasticity of the urethral sphincter was given however. Our finding of EMG activity which could be associated with a failure of relaxation of the urethra suggests a possible mechanism.

The women in this study, with the most severe persisting urinary retention, had large atonic bladders, presumably resulting from long term overdistention. Preceding the onset of retention, several of these women had histories of increased urinary fre- 
quency. This may explain why we and others ${ }^{235}$ have found abnormal EMG activity in patients not yet with retention.

Theoretically, by abolishing abnormal muscle activity relaxation of the sphincter could be improved and voiding restored, provided the bladder had not been damaged by prolonged overdistention. A trial of the effect of phenytoin is currently in progress.

We thank Mr RT Turner-Warwick, Mr E Milroy, Mr P Worth, Mr J Osborne and Mr J Steele for permission and encouragement to study their patients. We are grateful to Sir Roger Bannister, Dr Morgan-Hughes, and Dr $\mathrm{R}$ Guiloff for referring patients. We wish to thank Dr Robin Willison for many very helpful discussions.

CJF was supported throughout these studies by the generosity of Ipsen-Beaufour International.

\section{References}

' Dibenedetto M, Yalla SV. Electrodiagnosis of striated urethral sphincter dysfunction. J Urol 1979;122:361-5.

${ }^{2}$ Butler WJ. Pseudomyotonia of the periurethral sphincter in women with urinary incontinence. J Urol 1979; 122: 838-40.

${ }^{3}$ Potenzoni D, Juvarra G, Bettoni L, Stagni G. Pseudomyotonia of the striated urethral sphincter. $J$ Urol 1983;130:512-3.

4 Blaivas JG. Sphincter electromyography. Neurourol Urodynam 1983;2:269-88.

s Dyro FM. Bauer SB, Hallett M, Khoshbin S. Complex repetitive discharges in the external urethral sphincter in a pediatric population. Neurourol Urodynam 1983; 2:39-44.

${ }^{6}$ Fowler CJ, Kirby RS. Abnormal electromyographic activity (Decelerating Burst and Complex Repetitive Discharges) in the striated muscle of the urethral sphincter in 5 women with persisting urinary retention. Br J Urol 1985;57:69-70.

${ }^{7}$ Fowler CJ, Kirby RS, Harrison MJG, Milroy EJG, Turner-Warwick R. Individual motor unit analysis in the diagnosis of disorders of urethral sphincter innervation. J Neurol Neurosurg Psychiatry 1984;47:63741.

${ }^{8}$ Hughes RC, Matthews WB. Pseudo-myotonia and myokymia. J Neurol Neurosurg Psychiatry 1969;32:11-14.

${ }^{9}$ Kimura J. In: Electrodiagnosis in Diseases of Nerve and Muscle. Kimura J ed. Philadelphia. FA Davis.

${ }^{10}$ Swash M. Schwartz M. In: Neuromuscular Diseases. Swash $M$ and Schwartz M eds. Berlin. Springer-Verlag 1981.

"Vodusek DB, Janko M, Kralj B. Electromyography of the pelvic floor muscles in incontinent female patients. Zdravstveni Vestnik 1979;48:577-8.

12 Stalberg E. Trontelj AV. Abnormal discharges generated within the motor unit as observed with singlefiber electromyography. In: Abnormal Nerves and Muscles as Impulse Generators. Culp WJ, Ochoa J, eds Oxford. Oxford University Press. 1982:443-74.

13 Trontelj J, Stalberg E. Bizarre repetitive discharges recorded with single fibre EMG. J Neurol, Neurosurg Psychiatry 1983;46:310-6.

14 Willison RG. Spontaneous discharges in motor nerve fibres. In Abnormal Nerves and Muscles as Impulse Generators. Culp WJ, Ochoa J, eds, Oxford. Oxford University Press. 1982:383-92.

15 Farrar DJ, Osborne JL. Voiding dysfunction in women. In: Urodynamics. Mundy AR, Stephenson TP, Wein AJ, eds. Edinburgh: Churchill Livingstone 1982:242-8.

${ }^{16}$ Larsen JW, Swenson WM, Utz DC, Steinhilber RM. Psychogenic urinary retention in women. JAMA 1963; 184:697-700.

${ }^{17}$ Margolis GJ. A Review of literature on psychogenic urinary retention. J Urol 1965;94:257-8.

18 Allen TD. Psychogenic urinary retention. South Med J 1972;65:302-4.

19 Emmett JL, Love JG. Vesical dysfunction caused by protruded lumbar disk. J Urol 1971;105:86-91.

${ }^{20}$ Raz S, Smith R. External sphincter spasticity syndrome in female patients. $J$ Urol 1976;115:443-6. 